\title{
Current problems of patriotic education of future psychologists of education as the constituent of all-professional training
}

\author{
Tatyana Molodtzova, Olga Efremova*, Svetlana Shalova, and Larisa Kobysheva \\ Taganrog Institute of A.P. Chekhov (Branch) of Rostov State University, 347936 Taganrog, \\ Russian Federation
}

\begin{abstract}
The current problems of patriotic education of bachelors and undergraduates of psychology and pedagogical education caused by insufficient formation at students of components of patriotic consciousness (cognitive, emotional, behavioural) are considered on the basis of the conducted empirical research. The author's technique of projective poll allowing to present a general characteristic of these components and level of patriotic consciousness of students according to stages of moral development (according to L. Kolberg)is used for diagnostics. Special attention is paid to a behavioural component of patriotic consciousness of students. The results presented in article allowed to reveal problems of improvement of patriotic education of future psychologists of education for the purpose of formation of their readiness for realization of spiritual education of children and teenagers on the basis of basic national values.
\end{abstract}

\section{Introduction}

The all-professional competence assuming readiness of graduates for creation of the bringing-up educational environment, for creation and realization of conditions and the principles of spiritual and moral education of pupils on the basis of basic national values is marked outin modern standards of the higher psychology and pedagogical education on levels of a bachelor degree and magistracy. The formation at future psychologists of patriotic consciousness acts as a fundamental factor of manifestation of this competence and a condition of realization of a personal example at the solution of problems of pedagogical, design, organizational and administrative, cultural and educational activity. This circumstance is especially important in the conditions of cross-border education in the modern world, activization of the international interaction of student's youth.

Nowin Russia the work performed on patriotic education focuses primarily on the problems of the Great Patriotic War leaving insufficiently cover for other areas of history and culture, economy and politics of the country, territory, region, city / village. Although military-patriotic education is given an important place, the civil-law education is carried out on a smaller scale.

\footnotetext{
* Corresponding author: efrem.olg@yandex.ru
} 
Another relevant focus of patriotic education in modern school is familiarizing the students to the delight of the natural wealth and culture of his native land. This is not intended however to dispel a negative image of the Russians shared by many conformists and created by interpreters of Russian fairy tales, that in the meantime in other fairy tales shows a lot of positive qualities such as diligence, self-control, worldly wisdom, openness, generosity, heroism.

In fact work on formation at school students of key competence of vital designing taking into account a civic attitudes of the young man as patriot, accomplice of the events defining history and the culture of the Fatherland in general and the small Homeland in particular is not conducted. Assistance in work of educational institutions on spiritual moral education of school students on the basis of national values can successfully be carried out on condition of formation at psychologists of formation of such components of patriotic consciousness as cognitive, emotional and behavioural [1].

The patriotic education implies as the starting phase of planning work on patriotic education of citizens, the analysis features of patriotic awareness of children and youth and psychological characteristic manifestations specificity of these groups a sense of patriotism. Development of a diagnostic framework to investigate into the patriotic awareness of today's youth is an important factor in optimizing the operation of educational institutions on patriotic education

\section{Materials and methods}

The article is based on sociological and psychological and pedagogical research problems of patriotism, made by modern Russian scientists, as well as the development of the theory of moral consciousness L. Kohlberg. Methods used: phenomenological and problem analysis; projective student survey.

\section{Discussion}

Integral expression of the individual's patriotic awareness of is a sense of patriotism. The sense of patriotism is one of the most difficult ethical (moral) senses that express the relation of man to other people, to the country, to his family, to himself.

Analyzing the different types of attitudes, A. N.Malinkin justifies the the differences between true patriotism and its substitutes: such as affective patriotism manifested under the influence of patriotic impulses; pseudo-patriotism, disguising hatred and contempt for the motherland under a special kind of love; counterpatriotism (love for an ideal, utopian image of the motherland [2].

Several researchers confirm a significant impact of the media upon mass consciousness of youth. It is noted that unpatriotic position of domestic media is focused on the "new thinking" in terms of increasing "humanistic values" tendentiously understood on the Western model of freedom and democracy. This trend, which is determined as Westernization, leads to the formation among young people neglect for everything domestic and certainly does not contribute to the development of patriotic awareness.

Another negative trend is the criminalization of social consciousness as a whole. Under the influence of the criminal layer, that introduced itself in almost all spheres of Russian society, people's attitudes to traditional Russian values such as justice, mercy, selfrealization in the workplace, etc. has changed. OriginalRussian national values and traditions are not shared by all citizens; some values (for instance, helping one's neighbor, a sacrifice for the common good) are often but declared by our compatriots and are mostly addressed to other people rather than to themselves, without becoming regulatory factors of 
behavior. As is noted by V.E.Shlapentokh, a significant damage to labor ethics was caused by instant enrichment of individuals in the post-perestroika era. Young peoplecommonly aspire to obtain wealth for nothing, without effort or labor, many young men and women have formed a dismissive attitude toward morality, work [3].

Our analysis of modern research has allowed us to highlight the structure of the sense of patriotism which contains three components. The cognitive component includes representations of the person about their country, its people, its culture, its civic duty, of the significance of the motherland for its citizens. The emotional component integrates a set of experiences that reflect the feeling of love of man for the country, its culture, language, nature, history. The behavioral component is a manifestation of these emotions in behavior and human activity.

For level characteristics of patriotic awareness and its manifestations in the behavior of young people it is advisable to refer to the development theory of moral thought by L. Kohlberg [4]. A true sense of patriotism is respective to the postconventional moral reasoning of a personality (according to L. Kohlberg), which is characterized by developing their own moral principles, beliefs, and ascension to universal human values. Many young men and women, according to L. Kohlberg, do not reach this level taking the imposed from outside norms of the reference group (conventional level of moral thought) or guided by respect for the moral norms only by considerations of personal gain (preconventional level). According to the six stages of moral thought, described by L. Kohlberg, we can number six levels and types of motives that determine the behavior of the person as a citizen.

The motives of the two stages of the preconventional level are: 1) avoidance of punishment or personal inconvenience, 2) the pursuit of gain; motives of conventional level steps are as follows: 3 ) approval by the reference entities, 4) focus on the norms dictated by the reference group; motives of the two stages of postconventional morality level are as follows: 5) commitment to the implementation of one's duty, 6) the need to live by the laws of conscience and the avoidance of self-deprecation.

In contemporary investigation into the problem of patriotic awareness of the Russian youth, significant divergence of the cognitive, emotional and behavioral components of patriotism is stated. So, the researchers note the hard pragmatism of the world view of today's young people who often consider themselves patriots of Russia, their commitment to the Western ideals of careerism and social success, often - rejection made in the national culture of moral standards.For example, L. Yu.Nikiforov and M.A. Soloviev [5] found that in most cases students identify themselves with the Russian ethnic group, but they deny the manifestation at the typical qualities of the Russian people (including, according to them, alongside with kindness, generosity, openness, patience, spirituality negative features passivity, lack of expressed diligence, punctuality, carelessness, lack of responsibility). The authors explain that the students are guided by the personal qualities that can ensure sustainable success in today's society: activity, initiative, initiative, diligence, punctuality, responsibility.

The study, conducted by S. Yu Shalova, led to the conclusion that the majority of students have developed a certain a moral ideal, close to the generally accepted one. However, the value orientation of the students themselves is far from ideal. This is most noticeable when analyzing terminal values [6].

The study by G.A. Bykovskaya, I.V. Inozemtsev, N. Zlobin [7] has revealed that $68.4 \%$ of young people state the personal significance of their nationality, at the same time, their priority values are westernized: health and physical strength, material well-being, education, freedom and independence; in the "tail" of the list of preferences are the love for Russia and spiritual wealth. The vast majority of students, according to this study, feel a sense of pride for Russia's success in the World War II, for the victories of our athletes and artists, but at the same time $32 \%$ of respondents would like to live outside Russia. A.V. 
Potemkin noted that representatives of the Russian national-ethnic group find values of the society, where they live, significant; at the same time they lack the motivation to implement the expressed patriotism and understanding of the purpose and patriotism [8].

Discordance between the different components of a sense of patriotism can be also related to the paradox, described by L.G Pochebut. The mentality of the Russians, as the author notes, is characterized by a desire to gain the approval and respect of others, by the desire to establish friendly relations with them; when building relationships particular importance is given to the professional field, and one's abilities.

However, the dominant focus on human evaluation in the society is not in the aspect of professional competence, but in the person's loyalty in the professional community (in particular - in relations with the administration) and solidarity.

By requiring the competence from a personality, the society estimates them according to the degree of loyalty; rules do not comply with sanctions: people are encouraged and punishedfor the degree of loyalty manifestation, of rather than for the results of labor. Thus, awareness of the values is in conflict with the unconscious motives to be loyal, conformist. In Western (European) culture the orientation at the professional competence and community evaluation are the same, therefore there is no divergence between the awareness of the difference rules, experiences and behavior motive.

According to L.G Pochebut patriotic awareness of the Russian people is characterized by collectivism which is the antithesis to individualism. High levels of individualism, according to the author, appear today in social groups of young people and business representatives. Young people differ from the older by a more pronounced individualist, risk appetite and the desire to achieve. According to the author, traditional collectivist culture is being transformed into modern Western individualistic culture in modern Russia [9, p. 250].

\section{Results}

The aim of the empirical study conducted by us was to identify the characteristics of patriotic consciousness of students.

We have assumed that in the present socio-cultural situation, when pro-Western values are cultivated, there is dissatisfaction with the many political and economic reforms in the country, young people find it difficult to self-identify as citizens, representatives of national culture, there is a rejection of many aspects of the national culture, which negatively It affects the development of patriotic awareness.

The research was conducted in Taganrog on expanded selection: 122 students of the Taganrog institute of named after A.P. Chekhov (branch) of Rostov State University of Economics. students in the Psychology and Pedagogical Education direction participated in poll.

To identify the characteristics and level of formation of each of the components of a sense of patriotism among students O.I. Efremova alongside with I. D. Leachman have developed a special diagnostic technique. While developing the technique particular attention was paid to the behavioral component of patriotism - its real manifestation in practice [10].This is due to the fact that young people are characterized by the contradiction between the declaration of patriotism and their true feeling, the awareness of the motherland and family values, and the behavior which is inappropriate to these values. For ensuring reliability of answers of examinees, the indirect projective questions providing characteristic future psychologists of formation of the attitude of their peers towards Russians, today's problems of the Russian society to Don region and hometown, family as to the small Homeland, to performance of a civic duty were formulated. 
Analysis of the results demonstrated that the majority of students manifest the emotional aspect of a sense of patriotism. This suggests concern (non-indifferent attitude) of young people to the country as a whole and with respect to the Homeland and the family.

In a characteristic of typical Russians (1 block), many students $(46.7 \%)$ gave a negative evaluation and $21.3 \%$ of those surveyed were uncertain (found it difficult to answer). Therefore, we can conclude that the students formed predominantly negative image of a typical Russian. According to many, the Russian people feature the following: slave psychology, laziness, alcoholism, passivity and dependence, lack of restraint, flat humor, carelessness, lack of manners. Uncritical acceptance and mythologizing concepts of natural laziness, passivity and alcoholism are significant for the development of Russian civil and professional consciousness of students and require correction, which is reflected in the motives of behavior. Socially active and successful students, as shown in the study by L. I. Kobysheva [11], have a positive image of the typical Russians.

Emotionally, most young people take an active interest in the current problems of the country, believe in the positive prospects, want to benefit the society. In $61 \%$ of cases observed not indifferent, interested attitude of the respondents to the current problems of the country. However, this attitude is not entirely implemented in behavioral terms, besides a large number of young people (more than a third, which is a critical mass) shows a negative emotional attitude to what is happening in a country experiencing contempt, rejection or apathy, detachment, indifference, taking an outside observer position .

When analyzing the behavioral component of the manifestations of patriotism among students a tendency is found to follow Western fashion (preference for western movies, music, food, ways to organize a holiday, the adoption of the position of the consumer to a greater extent than the constructor, etc.). $71.3 \%$ of the respondents attribute typically proWestern behaviour trends to their peers. Some students opt for accommodation, education, medical treatment abroad. Boys mostly try to avoid serving in the army, would rather relax than work for the good of society. Many respondents also lack interest in natural and the cultural monuments of their native land, historical places, they lack concern in solving the region's problems, are unwilling to personally participate in its improvement, to work in the community. Neutral attitude to the region's problems was manifested by the respondents in $63.1 \%$ of cases.

The attitude to the family as to the homeland is not formed with more than a half of the surveyed students. In general, young people's attitudes to homeland to a lesser extent is characterized by care, thoughtful attitude, a desire to help, and to larger extent by consumer attitude, focus on relaxation and personal problems. Almost half of the cases ( $48.4 \%$ votes) indicated thepeers desire in every possible way to help parents, not to depend on them; However, in $51.6 \%$ of cases recorded consumer attitude to parents experiencing material and other difficulties.

In their aspirations and preferences, in social life, in respect to their Motherland as a whole, the native land, the family, the young people are not always guided by conscience and high moral principles and awareness of the true patriotic value. In $56 \%$ of cases answers reflecting conventional level of moral thought, by L. Kohlberg dominated (motives of approval of friends and meeting the requirements of the reference group). With $32 \%$ of the respondents there prevailed assessment, corresponding to the preconventional level (motives of punishment avoidance of and rewards motives). Only with $12 \%$ of respondents answers attributing motives peers postconventional level such as duty or conscience were prevalent.

\section{Conclusions}


The results of this study allow us to determine the relevant objectives and areas of work on patriotic education of youth. With a view to improving the work of educational institutions in the field of patriotic education is necessary to pay special attention to the following points:

- Work with youth should focus not only on the formation of a sense of patriotism, but also in the prevention of such phenomena as affective patriotism, pseudo-patriotism and counterpatriotism;

- An urgent diagnosis of youth patriotic awareness plays an important role in patriotic education. For this purpose, a technique may be used, which we have developed to diagnose the level of cognitive, emotional and behavioral components of patriotism in young people. During a collective discussion of diagnostic results, young people might have an opportunity to reconsider some of their judgments, change the emotional attitude to the problems of the country, to determine adequate manifestation of patriotism in the activities and behavior.

- It is expedient to carry out the analysis of features of patriotic consciousness at students with using of this technique on classes in social psychology, pedagogical psychology (section "Psychology of education"), development psychology (when studying the theory of development of moral consciousness by L. Kolberg).

- This technique can be applied by future psychologists of education during student teaching to studying of features of patriotic consciousness of school students. The analysis of results of the researches conducted with its help can act as a factor of the adjusting influence on a civic and professional stand of the students participating in creation of the bringing-up environment on the basis of national values.

\section{References}

1. O.I. Efremova, Bulletin of Saratov Regional Institute of Education Development. 4. 16-25 (2015)

2. A.N. Malinkin, Journal of Sociology. 1/2, 87-117 (1999)

3. V.E. Shlapentokh, Journal of Sociology. 4, 5-21 (1997)

4. L. Kohlberg, Human Development 1(51), 8-20 (2008)

5. L.Yu. Nikiforova, M.A. Solovieva, Abstracts of the International scientific-practical conference "Psychology of the XXI century" (St. Petersburg State University, St. Petersburg, 2002)

6. S.Yu. Shalova, Naukovedenie, 3(16), 100 (2013)

7. G.A. Bykovskaya, I.V. Inozemtsev, A.N. Zlobin, Bulletin of Samara Scientific Center of the RAS. (3)12, 15-24 (2010)

8. A.V. Potemkin, National-psychological features of personality manifestations of patriotism (Novosibirsk, 2009)

9. L.G. Pochebut, Social community. The psychology of the crowd, society, ethnos (Publishing House of St. Petersburg University, St. Petersburg, 2005)

10. O.I. Efremova, Concept. 4, 11-15 (2015)

11. L.I. Kobysheva, Society: psychology, sociology, pedagogy. 4, 73-77 (2013) 